\title{
Zona Pellucida Formation by Naked Mouse Oocytes Grown In Vitro
}

\author{
Takashi MIYANO, Yuji HIRAO'), Yoshi-hisa IKEDA \\ and Seishiro KATO
}

Department of Animal Reproduction, Faculty

of Agriculture and ${ }^{1)}$ The Graduate School of

Science and Technology, Kobe University,

Kobe 657, Japan

\begin{abstract}
Enzymatic dispersed small naked mouse oocytes from ovaries at birth were co-cultured with ovarian somatic cells for eight days in vitro, and the growth of oocytes and the formation of zona pellucida were examined. After enzymatic treatment of the ovaries at birth (Day 0 of culture), oocytes and ovarian cells were dispersed completely. The oocytes were 11-22 $\mu \mathrm{m}$ in diameter (average: $16.9 \pm 2.2 \mu \mathrm{m}$ ) and had no zona pellucida around them. From Day 1 of culture, oocytes and ovarian somatic cells aggregated, formed several clumps and oocytes grew inside or became attached to them. On Days 4, 6 and 8 of culture, 3.0, 6.0 and $35.3 \%$ of oocytes grew to 30 $\mu \mathrm{m}$ or more in diameter, respectively. Even on Day 8 of culture, no follicle formation was observed. At the periphery of the grown oocytes without surrounding somatic cells on the clumps, PAS-positive, indented zona pellucida-like materials were deposited. The materials reacted strongly with anti-mouse zona pellucida antibody in immunogold staining. Immuno-reactive materials were also observed in the oocyte cytoplasm, whereas no reaction was found in ovarian somatic cells. These results suggest that the zona pellucida was formed by the oocyte and deposited its periphery without follicle formation in mice.
\end{abstract}

Key words: Oocyte, Co-culture, Zona pellucida, Anti-zona pellucida antibody.

(J. Reprod. Dev. 40: 189-195, 1994)

月 fter birth, mouse oocytes increase in volume with arrested nucleus at the diplotene stage of the first meiotic prophase. Concomitant with an increase in the size of oocytes, the surrounding granulosa cells increase in number and the zona pellucida is formed between the oocyte and granulosa cells [1, 2]. It has remained unresolved until recently whether the zona pellucida originates from oocytes, granulosa cells, or both $[3,4]$. Bleil and Wassarman [5] demonstrated that the mouse oocyte itself formed zona pellucida pro-

Accepted for Publication: April 2, 1994

Correspondence: T. Miyano teins in their experiments in which radiolabeled amino acid ( ${ }^{35} \mathrm{~S}$-methionine) and sugar ( ${ }^{3} \mathrm{H}$-fucose) were incorporated into the zona pellucida of denuded growing oocytes. It has been suggested that the surrounding granulosa cells play a metabolically important role in the growth of oocytes via the gap junctions between them and the oocyte [6-8]. However, it remains unclear whether the commencement of the formation of the zona pellucida is regulated by the oocyte or by surrounding granulosa cells.

At birth, mouse oocytes in the ovaries are small, similar in size and have no zona pellucida around them $[2,9]$. In this study, small oocytes were ob- 
tained by enzymatic dispersion of ovarian tissues and the oocytes were co-cultured with ovarian somatic cells for eight days in vitro, during which the oocytes grew and formed a zona pellucida without follicular formation.

\section{Materials and Methods}

\section{Oocyte culture in vitro}

Naked oocytes were obtained from newborn mouse ovaries by the enzyme digesting methods described by Baran and Bachvarova [10]. Ovaries were collected from ddY female mice at birth under a dissecting microscope. They were washed twice in Eagle's minimum essential medium (MEM, Nissui Pharmaceutical Co., Ltd., Tokyo, Japan) supplemented with $50 \mu \mathrm{g} / \mathrm{ml}$ sodium pyruvate, and immersed in enzymatic solution containing $2 \mathrm{mg} / \mathrm{ml}$ pronase (Actinase-E, Kaken Co., Tokyo, Japan) in MEM at $37 \mathrm{C}$ for $30 \mathrm{~min}$. After washing in MEM, a group of eight ovaries was transferred into a plastic culture dish (No. 1008, 35 $\times 10 \mathrm{~mm}$, Falcon, Becton Dickinson Labware, Lincoln Park, NJ, USA) containing $2 \mathrm{ml}$ MEM supplemented with $10 \%$ fetal calf serum (FCS, Whittaker M.A. Bioproducts, Inc.) and gently pipetted for 3 min to disperse the oocytes and ovarian somatic cells. After the treatment, all of the oocytes and somatic cells in the ovaries dispersed completely. Oocytes and the cells were cultured at $37 \mathrm{C}$ under a humidified atmosphere of $5 \% \mathrm{CO}_{2}$ in air for eight days. The day the cells began to culture was designated Day 0 of culture.

On Days 2, 4, 6 and 8 of culture, oocyte diameters of approximately 200 oocytes were measured using an ocular micrometer (Nikon, Tokyo, Japan) connected to an inverted microscope. Since the oocytes and somatic cells were aggregated, forming several clumps in a culture dish from Day 1, the diameters of oocytes were measured after they were released from the clumps by pipetting. Diameters of oocytes obtained enzymatically from the ovaries of 2, 4, 6 and 8 day-old mice were measured in the same manner as controls.

\section{Preparation for anti-zona pellucida antiserum}

Mature female ddY mice were induced to ovulation by an intraperitoneal injection of 5 I.U. pregnant mare's serum gonadotropin (PMSG, Teikoku
Zoki, Tokyo, Japan) followed by an injection of 5 I.U. human chorionic gonadotropin (hCG, Sankyo Zoki, Tokyo, Japan) $48 \mathrm{~h}$ later. Ovulated eggs were collected from the oviducts 14-16 h after hCG injection. They were transferred into Dulbecco's phosphate buffered saline (PBS) containing 0.05\% hyaluronidase (Type I, Sigma, St. Louis, MO, USA) to remove cumulus cells. After twice washing in PBS, zonae pellucidae were stripped off mechanically from the eggs using a small bore pipet. Collected zonae pellucidae were washed in PBS and resuspended in a small volume of PBS. A total of 2,500 zonae pellucidae were dissolved in $3 \mathrm{ml}$ of PBS for $35 \mathrm{~min}$ at $65 \mathrm{C}$. An aliquot of this solution $(0.5 \mathrm{ml})$ was emulsified with an equal volume of Freund's complete adjuvant (Wako Pure Chemical Industries, Ltd., Osaka, Japan) and the resulting emulsion was injected into the back of a male New Zealand White rabbit. Five booster shots of the same amount of zona pellucida solution in Freund's incomplete adjuvant (Wako Pure Chemical Industries, Ltd., Osaka, Japan) were injected at intervals of 6-10 days. Ten days after the last injection, blood was collected from the carotid artery and clotted at room temperature. Anti-mouse zona pellucida antiserum was obtained following centrifugation of the blood and stored at $-20 \mathrm{C}$ before use. Serum obtained from the marginal vein of the ear of the same rabbit before immunization was used as preimmune serum.

\section{Histological examinations}

Some of the clumps formed during the culture period were examined histologically and immunohistologically. At the end of culture, they were fixed in $4 \%$ (para) formaldehyde solution, dehydrated in ethanol, embedded in methacrylate resin (JB-4, Polysciences, Inc., Warrington, PA, USA), and sectioned serially at $4 \mu \mathrm{m}$ thickness. Some sections were stained using the periodic acidSchiff method (PAS) and Ehrlich's hematoxylin. Other sections were used for immunohistological examination of zona pellucida antigen(s) using immunogold techniques.

Immunogold staining followed the techniques described by Morgan et al. [11]. Sections were incubated in a drop of PBS ( $\mathrm{pH}$ 7.2) containing $1 \%$ bovine serum albumin (Sigma, St. Louis, MO, USA) and $0.1 \%$ Thimerosal (Sigma, St. Louis, MO, USA) for $10 \mathrm{~min}$ at room temperature. This buffer was also used for dilution of the second antibody. Sec- 
tions were then incubated in the diluted antimouse zona pellucida antiserum (1:100) for $60-90$ min. After washing with the buffer, a drop of diluted $1 \mathrm{~nm}$ colloidal gold particles conjugated goat anti-rabbit immunoglobulins antibody (1:40, Amersham Japan, Tokyo, Japan) was poured on the sections and they were incubated for $40 \mathrm{~min}$. Sections were washed with PBS, then distilled water for $10 \mathrm{~min}$, and the gold particles were intensified by silver reagent (IntenSEM kit, Amersham Japan, Tokyo, Japan) for $15 \mathrm{~min}$. Preimmune serum was used for the first antibody as a control.

\section{Results}

\section{Oocyte growth in vitro}

At the beginning of culture, the small, dispersed oocytes and ovarian somatic cells (Fig. 1A) aggregated to form several clumps during the culture period, and the oocytes became attached to the surface (Fig. 1B). Some ovarian somatic cells became attached to the bottom of the culture dish and overgrew it, whereas floating naked oocytes degenerated during the culture period.
Changes in the distribution of the diameters of the oocytes in vivo and in vitro were shown in Fig. 2. At birth, the oocytes, which were 11-22 $\mu \mathrm{m}$ in diameter (average: $16.9 \pm 2.2 \mu \mathrm{m}$ ), developed in the ovaries. A small proportion of oocytes appeared to grow and most of the oocytes remained small in size in the ovaries. At 2, 4, 6 and 8 days old, $3.5,10.0,11.5$ and $21.5 \%$ of them were $30 \mu \mathrm{m}$ or more, respectively. The maximum diameters of the oocytes in the ovaries were $38,40,48$ and 56 $\mu \mathrm{m}$, respectively. In vitro-cultured oocytes grew in a similar manner. On Days 4, 6, and 8 of culture, $3.0,6.0$ and $35.3 \%$ of oocytes grew $30 \mu \mathrm{m}$ or more, respectively. However, most of the oocytes at the diameter of $20 \mu \mathrm{m}$ or less had degenerated by Day 8 .

\section{Zona pellucida formation of oocytes}

Specificity of the anti-mouse zona pellucida antiserum was tested immuno-histologically. The antiserum did not react with control tissues such as mouse liver, spleen and kidney (data not shown). No binding was observed in ovarian somatic cells other than the zona pellucida in the ovaries from mature female mice (Fig. 3). Control preimmune serum showed no reaction with the control tissues or the ovaries. The maximum titer
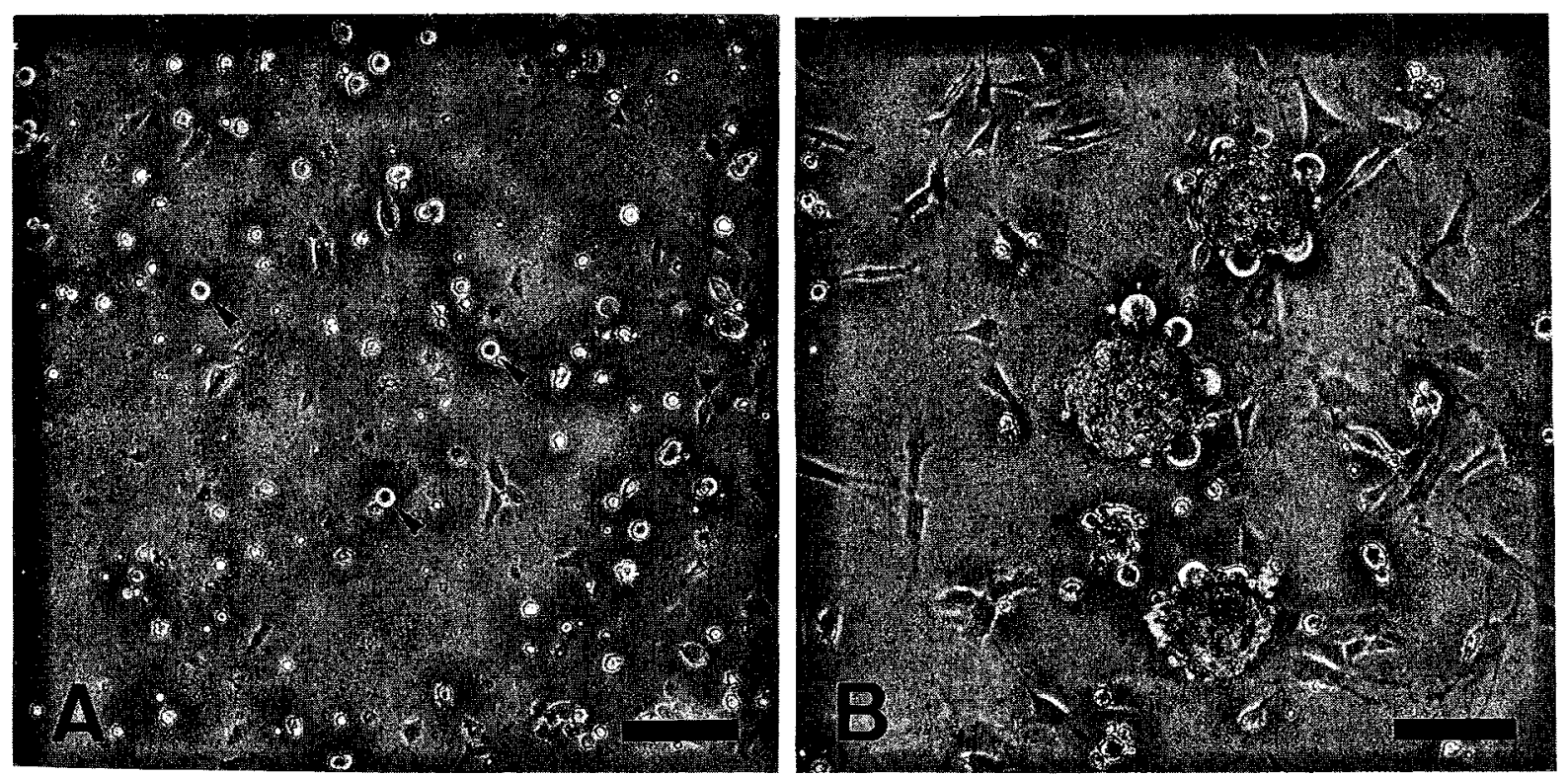

Fig. 1. Photomicrographs of in vitro growth of mouse oocytes co-cultured with ovarian somatic cells on Day 0 (A) and Day 8 (B) of culture under an inverted microscope. Naked oocytes (arrow heads) and dispersed ovarian cells were obtained from pronase treated ovaries at birth (A). Oocytes and ovarian cells aggregated to form several clumps, and oocytes attached on the surface and grew (B). Some ovarian somatic cells attached to the bottom of the culture dish and overgrew it. Bars in the figures represent $100 \mu \mathrm{m}$. 

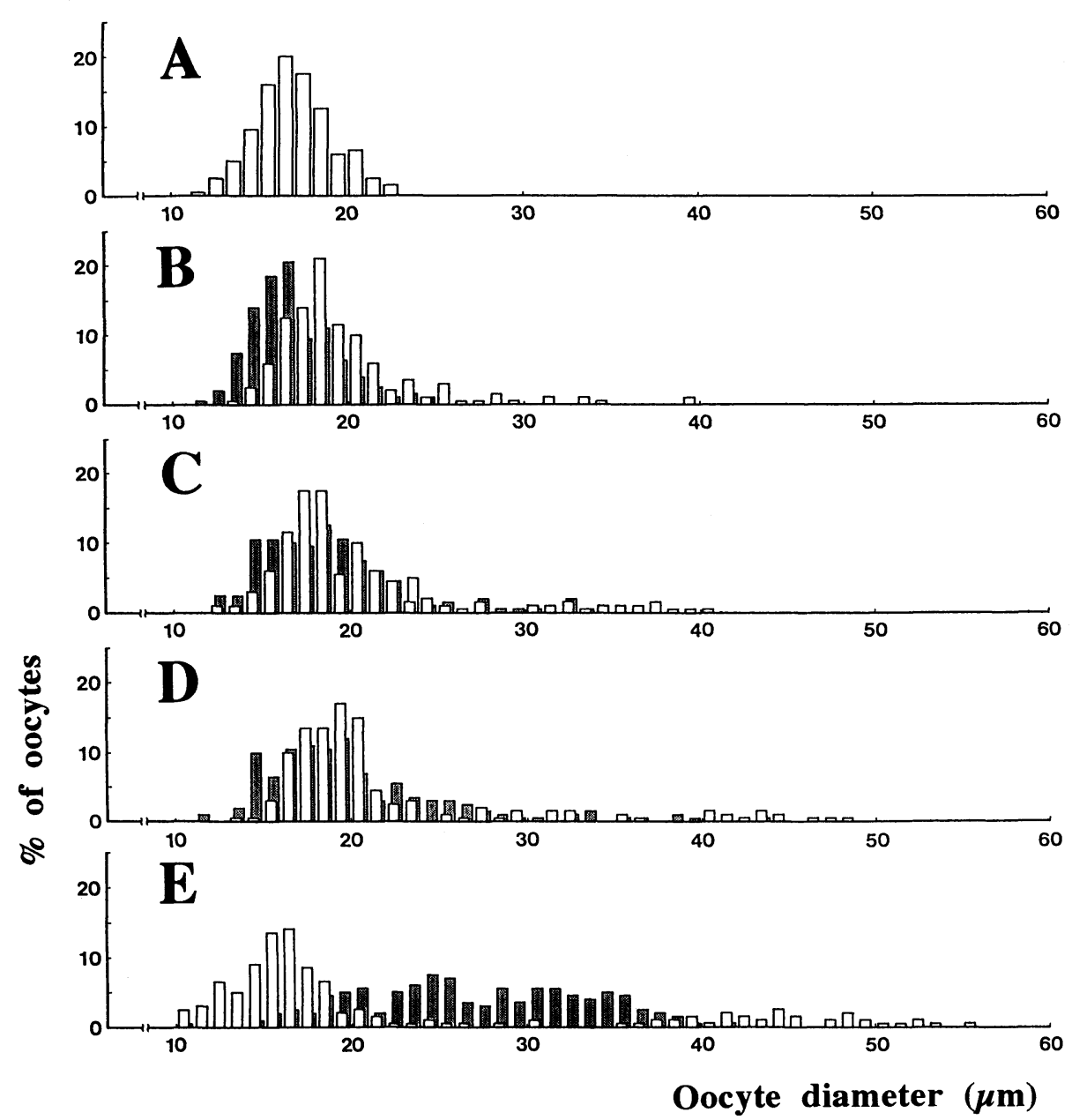

Fig. 2. Changes in the size distribution of mouse oocytes grown in vivo and in vitro. Hatched bars in figures A, B, C, D and E represent the distributions of oocyte diameters on Days 0, 2, 4, 6 and 8 of culture, respectively. Empty bars in each figure show the distribution of oocyte diameters from ovaries of mice at the same chronological age. Diameters of approximately 200 oocytes were measured for each group.

of the antiserum, as tested to the zona pellucida in the ovaries, was 1:1280.

In the histological examinations, the oocytes developed with attachment to the surface of the clumps and were also enclosed by them (Fig. 4A). Even on Day 8 of culture, all of the ovarian somatic cells in clumps had a flattened shape, and no follicle formation with the granulosa cells seen in the ovaries of 8 day-old mice was observed. A layer of PAS-positive zona pellucida-like materials was deposited around several oocytes in the clumps, which reacted with the anti-zona pellucida antibody in immunogold staining. Oocytes growing on the surface of the clumps also had PAS-positive, immuno-reactive materials around them (Figs. 4B and C). However, the outline was indented, especially in the portion without surrounding somatic cells, that was exposed directly to culture medium. Immuno-reactive materials were also observed in the oocyte cytoplasm, whereas no reaction was found in ovarian somatic cells (Fig. 4C).

\section{Discussion}

Oocytes grew over $30 \mu \mathrm{m}$ in diameter, attaching to the surface of clumps which consisted of ovarian cells, while floating naked oocytes degenerated during the culture period. Bachvarova et al. 

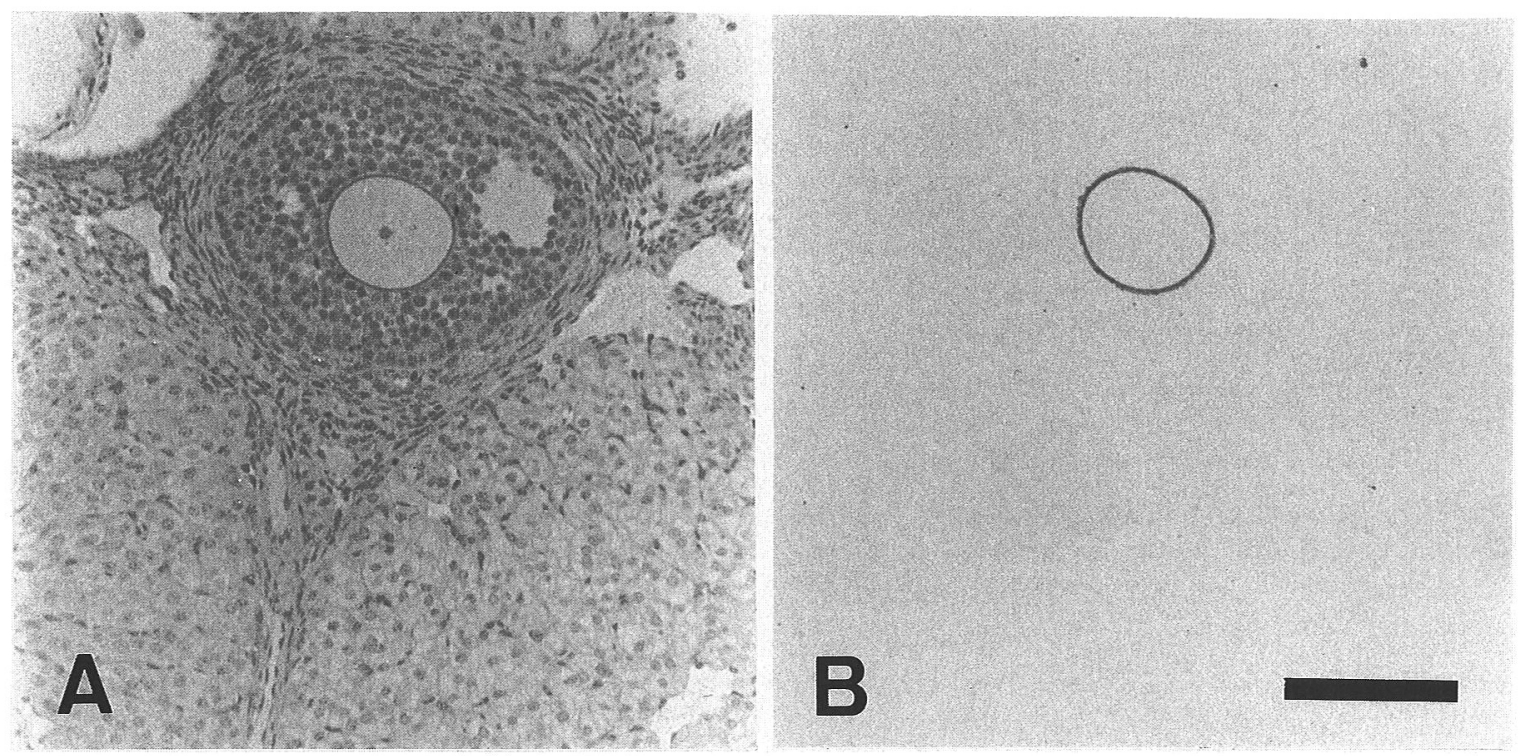

Fig. 3. Reaction of the anti-mouse zona pellucida antiserum in an ovarian section from a mature female mouse. One section was stained with the periodic acid Schiff method (PAS) and hematoxylin (A). A serial section was stained by immunogold technique using anti-zona pellucida antiserum (B). Only the zona pellucida was stained. Bar in the figure represents $100 \mu \mathrm{m}$.
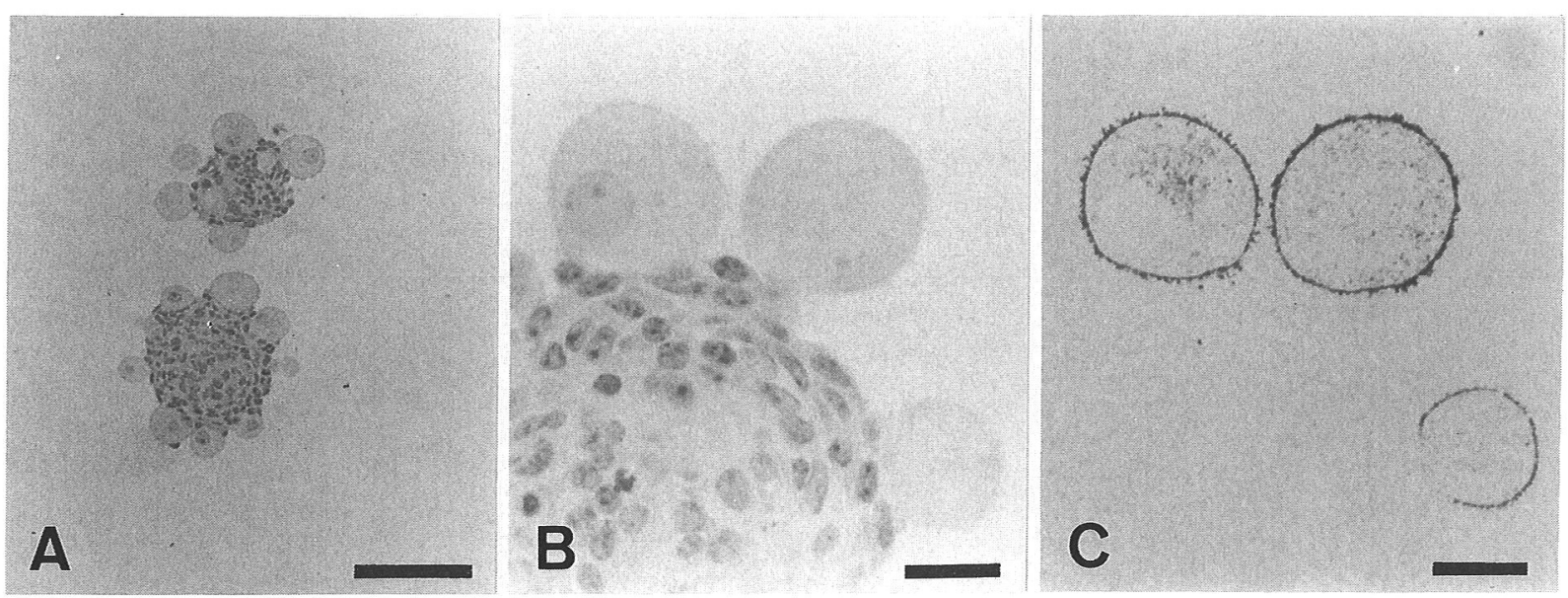

Fig. 4. Histological sections of clumps after eight days of culture, which consisted of growing mouse oocytes and ovarian somatic cells. Oocytes grew in the clumps as well as on their surface (A). PAS-positive zonae pellucidae formed around growing oocytes at the periphery of the clumps (B). These zonae pellucidae reacted with the anti-mouse zona pellucida antiserum in immunogold staining (C). Immuno-reactive materials were also observed in the oocyte cytoplasm, whereas no reaction was found in ovarian somatic cells. Bars in figures A, B and C represent 100,20 and $20 \mu \mathrm{m}$, respectively.

[12] described a culture system in which ovarian cells attached to the culture dish and naked growing oocytes remained on the monolayer. In their system, oocyte growth occurred only in the presence of ovarian cells, while naked oocytes cultured in the absence of the cells did not grow. Our results agree with their result. It has been reported that growth of denuded mouse oocytes is not sup- ported by Sertoli cells or 3T3 cells, although metabolic cooperativity of oocytes and the co-cultured monolayer of the cells was displayed at the same levels as those of the follicle cells [13]. Eppig [14, 15] reported that oocyte growth occurred in vitro only when granulosa cell-oocyte gap junctional contacts were present. All these studies suggest that contact between oocyte-granulosa cells or oo- 
cyte-ovarian cells is required for oocyte growth. Although we haven't identified the attached ovarian cells as granulosa cells, metabolic coupling was thought to be maintained between the ovarian somatic cells and the grown oocytes.

In our immunogold experiments, a zona pellucida formed around the growing oocytes in spite of the presence of surrounding ovarian cells. Immuno-reactive materials with anti-zona pellucida antibody were present in the oocyte cytoplasm, whereas no reaction was found in clumps consisted of ovarian somatic cells. This histological evidence suggests that the zona pellucida is formed by the oocyte itself. Several lines of biochemical studies are now available to support the evidence that mouse zona pellucida glycoproteins are synthesized by oocytes themselves $[1,5,16-$ 18]. Polyclonal antisera and monoclonal antibodies directed against the zona pellucida detect proteins, or precursors of the proteins, in oocytes, but not granulosa cells or other cell types [16, 19]. These findings suggest that zona pellucida proteins originate from oocytes, not granulosa cells. Furthermore, the presence of granulosa cells possibly increases the number of radiolabeled precursors incorporated into zona pellucida proteins as a consequence of greater uptake of radioactively labeled precursors by the granulosa cells [5].

Besides the origin of the zona pellucida, it is unclear whether the formation of the zona pellucida is regulated by oocytes or surrounding granulosa cells. In the ovaries, patches of the zona pellucida appeared around oocytes of $33 \mu \mathrm{m}$ in diameter, and a continuous layer of zona pellucida was formed around the oocytes over $39 \mu \mathrm{m}$ in diameter [2]. Concomitant with the zona pellucida formation, granulosa cells change their form from flattened to cuboidal shape and increase in number. It has been shown that the zona pellucida formed around the oocyte in organ-cultured newborn mouse ovaries, in which surrounding granulosa cells maintained their flattened shape [20, 21]. In the present study, small oocytes from newborn mice began to form a zona pellucida without follicle formation. Although we have not determined clearly for the relationship between oocyte diameter and the formation of zona pellucida in this study, most of the oocytes grown over $30 \mu \mathrm{m}$ in diameter had a zona pellucida. This result suggests that the size of oocytes regulates the beginning of zona pellucida formation.

\section{Acknowledgment}

We thank F.B.P. Wooding in AFRC Institute, Cambridge, U.K. for helpful discussion of immunogold techniques.

\section{References}

1. Wassarman PM. Zona pellucida glycoproteins. Ann Rev Biochem 1988; 57: 415-442.

2. Miyano T, Hirao Y, Kato S, Kanda S. Formation of zona pellucida in relation to the oocyte growth in the mouse ovary. Jpn J Anim Reprod 1988; 34: 61-66 (In Japanese).

3. Tsafriri A. Oocyte maturation in mammals. In: Jones RE (ed.), The Vertebrate Ovary. New York: Plenum Press; 1978: 409-442.

4. Tesoriero JV. Comparative cytochemistry of the developing ovarian follicles of the dog, rabbit, and mouse: origin of the zona pellucida. Gamete Res 1984; 10: 301-318.

5. Bleil JD, Wassarman PM. Synthesis of zona pellucida proteins by denuded and follicle-enclosed mouse oocytes during culture in vitro. Proc Natl Acad Sci USA 1980; 77: 1029-1033.

6. Anderson E, Albertini DF. Gap junctions between the oocyte and companion follicle cells in the mammalian ovary. J Cell Biol 1976; 71: 680-686.
7. Heller DT, Cahill DM, Schultz RM. Biochemical studies of mammalian oogenesis: metabolic cooperativity between granulosa cells and growing mouse oocytes. Dev Biol 1981; 84: 455-464.

8. Brower PT, Schultz RM. Intercellular communication between granulosa cells and mouse oocytes: existence and possible nutritional role during oocyte growth. Dev Biol 1982; 90: 144-153.

9. Odor DL, Blandau RJ. Ultrastructural studies on fetal and early postnatal mouse ovaries; II. Cytodifferentiation. Am J Anat 1969; 125: 177-216.

10. Baran MM, Bachvarova R. In vitro culture of growing mouse oocytes. J Exp Zool 1977; 202: 283-289.

11. Morgan G, Wooding FBP, Brandon MR. Immunogold localization of placental lactogen and the SBU-3 antigen by cryoultramicrotomy at implantation in the sheep. J Cell Sci 1987; 88: 503-512.

12. Bachvarova $R$, Baran $\mathbf{M M}$, Tejblum A. Development of naked growing mouse oocytes in vitro. J Exp Zool 1980; 211: 159-169. 
13. Buccione $R$, Cecconi $S$, Tatone C, Mangia F, Colonna R. Follicle cell regulation of mammalian oocyte growth. J Exp Zool 1987; 242: 351-354.

14. Eppig JJ. Mouse oocyte development in vitro with various culture systems. Dev Biol 1977; 60: 371-388.

15. Eppig JJ. A comparison between oocyte growth in coculture with granulosa cells and oocytes with granulosa cell-oocyte junctional contact maintained in vitro. J Exp Zool 1979; 209: 345-353.

16. Greve JM, Salzmann GS, Roller RJ, Wassarman PM. Biosynthesis of the major zona pellucida glycoprotein secreted by oocytes during mammalian oogenesis. Cell 1982; 31: 749-759.

17. Shimizu S, Tsuji M, Dean J. In vitro biosynthesis of three sulfated glycoproteins of murine zonae pellucidae by oocytes grown in follicle culture. $J$ Biol Chem 1983; 258: 5858-5863.
18. Wassarman PM, Greve JM, Perona RM, Roller RJ, Salzmann GS. How mouse eggs put on and take off their extracellular coat. In: Davidson $\mathrm{EH}$ and Firtel RA (eds.), Molecular Biology of Development. New York: Alan R. Liss Inc; 1984:213-225.

19. Lévillé MC, Roberts KD, Chevalier S, Chapdelaine A, Bleau G. Formation of the hamster zona pellucida in relation to ovarian differentiation and follicular growth. J Reprod Fert 1987; 79: 173-183.

20. Miyano T, Hirao Y, Kato S, Kanda S. Growth of mouse oocytes in ovaries cultured in vitro. Jpn J Zootech Sci 1988; 59: 848-853 (In Japanese).

21. Hirao Y, Kimura J, Miyano T, Kato S. Effect of PMSG on early oocyte growth and follicular development in newborn mouse ovaries cultured in vitro. J Reprod Dev 1993; 39: 13-17. 